\title{
Relationship satisfaction in couples confronted with colorectal cancer: the interplay of past and current spousal support
}

\author{
Mariët Hagedoorn • Meirav Dagan · Eli Puterman • \\ Christiaan Hoff - W. J. H. Jeroen Meijerink • \\ Anita DeLongis · Robbert Sanderman
}

Received: June 29, 2010/Accepted: December 20, 2010/Published online: January 11, 2011

(C) The Author(s) 2011. This article is published with open access at Springerlink.com

\begin{abstract}
Based on attribution theory, this study hypthesized that past spousal supportiveness may act as a moderator of the link between one partner's current support behavior and the other partner's relationship satisfaction. A sample of 88 patients with colorectal cancer and their partners completed questionnaires approximately 3 and 9 months after diagnosis. The data were analyzed employing dyadic data analytic approaches. In the short-term, spousal active engagement-which involved discussing feelings and engaging in joint problem solving-was positively associated with relationship satisfaction in patients as well as in partners, but only when past spousal support
\end{abstract}

M. Hagedoorn · M. Dagan · R. Sanderman

Department of Social Sciences, University Medical Center

Groningen, University of Groningen, Groningen,

The Netherlands

E. Puterman

Department of Psychiatry, University of California,

San Francisco, CA, USA

A. DeLongis

Department of Psychology, University of British Columbia,

Vancouver, BC, Canada

C. Hoff

Department of Surgery, Medical Center Leeuwarden,

Leeuwarden, The Netherlands

W. J. H. J. Meijerink

Department of Gastro Intestinal Surgery, Free University

Medical Center, Amsterdam, The Netherlands

M. Hagedoorn ( $\square)$

Health Pyschology Section (FA 12), Department of Health Sciences, University Medical Center Groningen, University of Groningen, P.O. Box 196, 9700 AD Groningen, The Netherlands e-mail: Mariet.Hagedoorn@med.umcg.nl was relatively low. Spousal protective buffering-which involved hiding worries and fears and avoiding talking about the disease-was negatively associated with relationship satisfaction in patients, again only when past spousal support was relatively low. If past spousal support was high, participants rated the quality of their relationship relatively high, regardless of their partner's current support behavior. Over time, past spousal supportiveness was not found to mitigate the negative association between spousal protective buffering and relationship satisfaction. Overall, our results indicate that relationship satisfaction can be maintained if past spousal supportiveness is high even if the partner is currently not very responsive to the individual's needs, at least in the short-term.

Keywords Active engagement - Protective buffering · Marital quality · Attributions · Cancer · Longitudinal

\section{Introduction}

Coping with cancer is considered to be a dyadic affair, meaning that patients' adjustment is affected by their partners' behavior and adjustment, and vice versa (Berg and Upchurch 2007; Coyne and DeLongis 1986; Hagedoorn et al. 2008; Manne and Badr 2008). Although it is widely accepted that the examination of this dyadic coping process requires an understanding of the interpersonal context in which it occurs, to date few empirical studies have addressed this issue (Berg and Upchurch 2007). To begin to fill this gap, this study investigates past spousal supportiveness-i.e., the degree to which the spouse was generally responsive to the individual's needs before the couple was confronted with cancer-as an interpersonal factor in marital adjustment after a cancer diagnosis. Specifically, we 
will argue that spousal supportive behavior after a cancer diagnosis is associated with relationship satisfaction in patients as well as partners, in the short-term and possibly over time, depending on past spousal support.

Research on close relationships has shown that couples' behavior during their interactions has an influence on a variety of important relationship outcomes, including relationship satisfaction (e.g., Bradbury et al. 1995; Christensen and Heavey 1990; Henry et al. 2007; Manne et al. 2004) (For a review, see Bradbury and Karney 1993). For example, in the context of coping with breast cancer, women were found to be more satisfied with their relationships when their husbands showed more acceptance and less hostility during problem-solving conversations (Manne et al. 2004). In a similar vein, survey studies have shown significant associations between current supportive behavior of partners and relationship satisfaction in patients (Hagedoorn et al. 2000; Hinnen et al. 2008a; Kuijer et al. 2000; Langer et al. 2009) (See also, Bodenmann et al. 2006; Wunderer and Schneewind 2008). Specifically, spousal active engagement, defined as discussing feelings and engaging in joint problem solving, was found to be positively associated with relationship satisfaction in patients. In contrast, spousal protective buffering, which includes hiding worries and fears and avoiding talking about the disease, was found to be negatively associated with relationship satisfaction in patients.

However, it has been recognized that a behavior displayed by one partner in a marital interaction may vary in its effect on the other partner and the relationship as a function of how this latter partner understands or perceives the behavior (for reviews, see Bradbury and Fincham 1990; Bradbury et al. 2000). There is ample evidence that benign attributions about partner behavior, such as ascribing negative partner behavior to external causes and ascribing positive partner behavior to stable characteristics of the spouse, are positively associated with relationship satisfaction. This has been found both with respect to global attributions about partner behavior (e.g. Fincham and Bradbury 1987, 1993; Fincham et al. 1997; Graham and Conoley 2006) and attributions about specific partner behaviors or intentions (Waldinger and Schulz 2006). It can be assumed that the association between attributions and relationship satisfaction is reciprocal. However a longitudinal study (i.e., eight assessments in 4 years) among newlyweds has shown that "initial levels of attributions predicted changes in marital satisfaction more than initial satisfaction predicted changes in attributions" (Karney and Bradbury 2000; p. 295).

Based on Heider's work (1958), McNulty and Karney (2001) have described attributional processes within close relationships as one way in which individuals coordinate their specific and global perceptions of their partners and relationships. Attributional processes are stimulated especially if a specific partner behavior is negative or unexpected (Holtzworth-Munroe and Jacobson 1985). One example of this occurs when partners show a lack of active engagement after a cancer diagnosis, while they are expected to show involvement in discussions of feelings and to engage in joint problem solving. Individuals who have a positive global perception of the relationship have a tendency to make benign attributions about their partner's behavior, supposedly to maintain their satisfaction with the relationship. In line with this, prior studies have shown that individuals who scored high on overall perceived support within a relationship interpreted the same behaviors of significant others as more supportive than did individuals who scored low on overall perceived support (Lakey and Cassady 1990; Lakey and Dickinson 1994; Pierce et al. 1992; Ross et al. 1999). For example, in one experimental study of undergraduates and their mothers (Pierce et al. 1992), students were asked to give an unanticipated speech. Before and after their speech, they received standardized supportive notes they believed were written by their mother. Students who perceived their mothers as generally highly supportive (measured 1 week before the experiment), felt more supported by the notes than students who perceived their mothers generally to be less supportive. In a similar vein, past spousal supportiveness may stimulate benign attributions of current spousal supportive behavior after a cancer diagnosis, especially if the behavior is negative, and consequently moderate the association between current spousal behavior and relationship satisfaction.

\section{Overview of the current study}

In the beginning of their intimate relationships, people usually report high levels of satisfaction. However, this may change over time. Even high-functioning, happy couples face challenges and stressful events that may impact their relationship negatively. Long-term outcomes of a relationship may depend, in part, on how people integrate problems, stressful events, and one another's responses to such events, with their more global evaluations of the relationship (McNulty and Karney 2001). A diagnosis of cancer in one member of the couple and both partners' subsequent supportive behavior may be considered such a challenge.

Based on the ideas outlined above, we expect current spousal supportive behaviors to be associated with current and future relationship satisfaction in patients as well as partners. These associations, however, are thought to depend on their perceptions of past spousal supportiveness. Past spousal supportiveness is considered to be a global evaluation of the relationship within which current spousal supportive behaviors need to be coordinated. We did not 
measure attributions, but assume that patients and partners, who perceive past spousal supportiveness to be high rather than low, make benign attributions for one another's low levels of active engagement and high levels of protective buffering. As a consequence, we expect to find these individuals to be able to maintain high levels of relationship satisfaction even if spousal active engagement is low and spousal protective buffering is high. In contrast, we expect those who perceive past spousal supportiveness to be low, not be able to do so. Hence, we hypothesize that spousal active engagement is positively associated with relationship satisfaction in patients as well as partners, but only if past spousal supportiveness is perceived to be relatively low. Spousal protective buffering is hypothesized to be negatively associated with relationship satisfaction, again only if past spousal supportiveness is perceived to be relatively low. Relatively low levels of relationship satisfaction are expected in individuals who report low levels of spousal active engagement or high levels of spousal protective buffering combined with low levels of past spousal supportiveness. The interplay of past and current spousal support on relationship satisfaction will be examined crosssectionally as well as longitudinally.

\section{Method}

Participants and procedures

Participants were newly diagnosed persons with colorectal cancer and their intimate partners who were recruited from oncology clinics at eight participating hospitals in the three northern provinces of the Netherlands. These couples ( $n=88$ ) took part in a longitudinal study that included an observation task. Couples completed questionnaires at three assessment times, namely approximately three, five, and nine months after diagnosis. The current study reports on the first (i.e., acute phase) and last (i.e., post-treatment phase) assessments. The couples received an information letter and an informed consent form during an outpatient visit from their physician or nurse. A research assistant was available by phone to answer potential questions about the study. Couples who returned the consent form to the investigators were contacted by phone and received a baseline questionnaire. The research procedures were approved by the Medical Ethical Committees of all hospitals involved.

Patients with colorectal cancer were eligible if they were waiting for treatment or recently underwent surgery, were currently in an intimate relationship, and were between 18 and 75 years of age. Inclusion criteria for couples were fluency in Dutch, no documented hearing or cognitive impairments, and informed consent of both partners.
A total of 280 couples were eligible, of which 88 expressed a willingness to participate and filled out the baseline questionnaire. Comparisons between patients who declined participation and those who participated did not show sex, $C_{h i}^{2}(1,260)=1.08, \quad P=.30$, nor age differences, $t(236)=1.82, P=.07$. Follow-up data are available for 70 couples. Comparisons between couples who completed the follow-up assessment and those who were lost to follow up revealed no significant differences in any of the baseline variables under study.

The sample includes 29 female patients and 59 male patients and their partners. Most couples were married $(88 \%)$ and the mean length of their relationship was 33 years $(\mathrm{SD}=13$; range $=4-56)$. Patients and partners had a mean age of $61(\mathrm{SD}=10.0)$. The level of education of participants varied from elementary school to university degree: $12 \%$ finished elementary school only, $60 \%$ received secondary education, and $27 \%$ received higher vocational education or a university degree. About $18 \%$ of the participants had a paid job. The majority of the men were retired (51\% of the patients, $69 \%$ of the partners), whereas the modal occupation for women was homemaker (38\% of the patients, $34 \%$ of the partners).

Fifty percent of the patients were diagnosed with colon cancer and the other half with rectal cancer. The stage of the cancer varied: $19 \%$ stage I, $29 \%$ stage II, $45 \%$ stage III and $7 \%$ stage IV. The majority $(n=55 ; 63 \%)$ of the patients had received surgery and 20 of these patients received a colostomy. Forty patients were scheduled to have an(other) operation in the near future, of which (at least) 12 would receive a colostomy. About $36 \%$ of the patients had received or were still undergoing chemotherapy $(n=8)$, radiotherapy $(n=18)$, or chemoradiation $(n=4)$. Most patients reported that they believed they had a reasonable $(28 \%)$ to high $(68 \%)$ chance of being cured. The majority of the patients reported co-morbidities $(61 \%)$ and many partners (85\%) also indicated health complaints, such as hypertension, chronic back pain, and arthritis.

\section{Measures}

\section{Spousal active engagement and protective buffering}

Both patients and partners were asked to estimate to what extent the other one currently adopts active engagement and protective buffering strategies (e.g., patient active engagement is rated by the partner and partner active engagement is rated by the patient) in coping with the cancer experience. These measures were developed by Buunk et al. (1996) and have been used extensively (De Ridder et al. 2005; Hagedoorn et al. 2000; Hinnen et al. 2008a, b, 2007; Kuijer et al. 2000). The active engagement scale consists of five items (e.g. 'My partner asks me how I feel' and 'My partner tries 
to discuss it with me openly') and six items measure protective buffering (e.g. 'My partner just waves my worries aside' and 'My partner tries to act as if nothing is the matter'). All items were answered on a five-point scale ranging from never (1) to very often (5). Cronbach's alpha for the spousal active engagement scale was .83 (patients) and .85 (partners). Cronbach's alpha for the spousal protective buffering scale was .68 (patients) and .79 (partners).

\section{Past spousal supportiveness}

Participants completed the Mutual Communal Behaviors Scale (MCBS; Williamson and Schulz 1995; Williamson et al. 1998). The MCBS consists of five items that evaluate past communal behaviors directed toward the other individual (e.g., "If my partner was feeling bad, I tried to cheer him/her up," "I went out of my way to help my partner") and five items that evaluate past communal behaviors directed toward the respondent (e.g., "My partner seemed to enjoy responding to my needs," "My partner did things just to please me"). Participants were instructed to indicate the frequency of these behaviors before the cancer diagnosis on a four-point scale ranging from never (1) to always (4). The MCBS has good psychometric properties and is stable over time (Williamson and Schulz 1995). A factor analysis of the current data supported the two factor structure (explaining $57 \%$ of the variance), indicating a factor for provided communal behavior (eigenvalue $=1.139$ ) and one for received communal behavior (eigenvalue $=4.560$ ). We used the latter factor as an indicator of past spousal support $(\alpha=.80$ for patients; .83 for partners).

\section{Relationship satisfaction}

Participants' relationship satisfaction was assessed with the marital quality subscale of the Maudsley Marital Questionnaire (MMQ; Arrindell et al. 1983; Crowe 1978). This scale consists of 10 items, such as "Do you get enough warmth and understanding from your partner?", "How often do you consider divorcing your partner?". The items were answered on 9-point scales (ranging from 0 to 8), with higher scores indicating higher levels of satisfaction. The scale showed high internal consistency for both patients $(\alpha=.91$ at baseline and .88 follow-up) and partners ( $\alpha=.91$ at baseline and .92 at follow-up).

Data analysis

Analyses were done using HLM v6 software (Raudenbush and Bryk 2002) and employed the dyadic data analytic approaches described by Kenny et al. (2006). All data were centered around the sample mean prior to applying the files to the HLM v6 package (Kenny et al. 2006; Kreft et al.
1995) and two dummy coded variables were created, one for patients $(1=$ patient, $0=$ partner $)$ and one for partners $(1=$ partner, $0=$ patient) (Laurenceau and Bolger 2005). Next, we created separate predictor variables for patients and partners by multiplying each level 1 predictor variable by the dummy coded variables. Within the statistical package HLM, data were entered uncentered for each equation. The general intercept was removed and replaced with the dummy coded variables 'patients' and 'partners' (Kenny et al. 2006; Laurenceau and Bolger 2005). Using this approach, we examined associations between current spousal supportive behavior (CSSB) and relationship satisfaction (RS) for patients and their partners within the same model. Past spousal support (PSS) was included as a moderator and we performed separate analyses for active engagement and protective buffering. The model is presented as following:

$$
\begin{aligned}
\mathrm{RS}_{i j}= & B_{0 j}(\text { Patient })+B_{0 j}(\text { Partner })+B_{1 j} \mathrm{CSSB}_{\text {Patient }} \\
& +B_{1 j} \mathrm{CSSB}_{\text {Partner }}+B_{2 j} \mathrm{PSS}_{\text {Patient }}+B_{2 j} \mathrm{PSS}_{\text {Partnert }} \\
& +B_{3 j} \mathrm{CSSB} * \mathrm{PSS}_{\text {Patient }}+B_{3 j} \mathrm{CSSB} * \mathrm{PSS}_{\text {Partner }}+e i j
\end{aligned}
$$

In the longitudinal analyses, relationship satisfaction at follow-up was predicted by baseline current spousal supportive behavior (i.e., active engagement or protective buffering) and past spousal supportiveness, and their interaction, controlling for baseline relationship satisfaction.

\section{Results}

Bivariate associations

Correlations among the variables under study are presented in Table 1. Sex and role differences were found only for spousal active engagement. Specifically, male patients $(M=4.15, \mathrm{SD}=0.60)$ reported higher levels of spousal active engagement than did female patients $(M=3.74$, $\mathrm{SD}=0.77), t(86)=2.76, P=.007$. In addition, patients reported higher levels of spousal active engagement than did partners, $F(1,86)=5.34, P=.023$. Demographic and illness variables, including age, education, duration of the relationship, type of cancer (i.e., colon or rectal cancer), cancer stage, surgery before baseline (yes/no), were not related to any of the study variables.

Cross-sectional analyses

\section{Spousal active engagement and past spousal} supportiveness

The first analysis revealed main effects for active engagement and past spousal supportiveness. Specifically, patients 
Table 1 Pearson correlations, means and standard deviations for the variables under study

\begin{tabular}{|c|c|c|c|c|c|c|c|}
\hline & 1 & 2 & 3 & 4 & 5 & Mean & SD \\
\hline 1. Past spousal supportiveness & $.41 * * *$ & $.36 * * *$ & -.08 & $.45 * * *$ & $.58 * * *$ & 3.12 & 0.51 \\
\hline 2. Spousal active engagement & $.48 * * *$ & $.32 * *$ & $-.54 * * *$ & $.41 * * *$ & $.49 * * *$ & 4.01 & 0.68 \\
\hline 3. Spousal protective buffering & -.12 & $-.51 * * *$ & $.27 *$ & $-.24 *$ & $-.42 * * *$ & 2.24 & 0.62 \\
\hline 4. Relationship satisfaction at baseline & $.65^{* * *}$ & $.58 * * *$ & $-.32 * *$ & $.30 * *$ & $.85^{* * *}$ & 7.00 & 1.04 \\
\hline 5. Relationship satisfaction at follow-up & $.53 * * *$ & $.53 * * *$ & -.17 & $.69 * * *$ & $.36 * *$ & 6.87 & 1.09 \\
\hline Mean & 3.05 & 3.81 & 2.16 & 6.89 & 6.79 & & \\
\hline SD & 0.54 & 0.67 & 0.69 & 0.98 & 1.05 & & \\
\hline
\end{tabular}

Patient statistics are presented above the diagonal and partner statistics below the diagonal. Correlations between patient and partner variables are presented on the diagonal

$* P<.05, * * P<.01, * * * P<.001$

Table 2 Hierarchical linear model (HLM): concurrent associations between spousal support and relationship satisfaction as a function of past spousal supportiveness

\begin{tabular}{|c|c|c|c|c|c|c|c|c|c|c|}
\hline & \multicolumn{5}{|c|}{ Patient relationship satisfaction } & \multicolumn{5}{|c|}{ Partner relationship satisfaction } \\
\hline & $B$ & SE & $t$ & $P$ & $\mathrm{ES}(r)$ & $B$ & SE & $t$ & $P$ & $\mathrm{ES}(r)$ \\
\hline \multicolumn{11}{|l|}{ Active engagement analysis ${ }^{\mathrm{a}}$} \\
\hline Intercept & 7.00 & 0.09 & 75.02 & $<.001$ & - & 7.00 & 0.08 & 87.20 & $<.001$ & - \\
\hline Past spousal supportiveness (PSS) & 0.87 & 0.27 & 3.26 & .002 & .25 & 0.81 & 0.16 & 5.03 & $<.001$ & .37 \\
\hline Spousal active engagement (SAE) & 0.42 & 0.14 & 3.00 & .004 & .23 & 0.50 & 0.16 & 3.22 & .002 & .29 \\
\hline $\mathrm{PSS} \times \mathrm{SAE}$ & -0.86 & 0.35 & -2.50 & .014 & .19 & -0.47 & 0.20 & -2.35 & .020 & .18 \\
\hline \multicolumn{11}{|l|}{ Protective buffering analysis ${ }^{\mathrm{b}}$} \\
\hline Intercept & 7.01 & 0.09 & 81.18 & $<.001$ & - & 6.91 & 0.08 & 90.09 & $<.001$ & - \\
\hline Past spousal supportiveness (PSS) & 0.77 & 0.26 & 2.94 & .004 & .23 & 1.14 & 0.17 & 6.68 & $<.001$ & .46 \\
\hline Spousal protective buffering (SPB) & -0.34 & 0.18 & -1.92 & .057 & .15 & -0.34 & 0.12 & -2.93 & .004 & .22 \\
\hline $\mathrm{PSS} \times \mathrm{SPB}$ & 1.10 & 0.41 & 2.67 & .009 & .21 & 0.25 & 0.28 & 0.87 & .387 & .07 \\
\hline
\end{tabular}

Effect size $r$ for each $t$ was computed with the following equation: $r=\operatorname{sqrt}\left[t^{2} /\left(t^{2}+d f\right)\right]$

${ }^{\text {a }} d f=164$

${ }^{\mathrm{b}} d f=162$

as well as partners who reported more spousal active engagement, $B_{\text {patients }}=0.42, \mathrm{SE}=0.14, t(164)=3.00$, $P=.004$, ES $r=.23$ and $B_{\text {partners }}=0.50, \mathrm{SE}=0.16$, $t(164)=3.22, P=.002$, ES $r=.29$, and more past spousal supportiveness, $B_{\text {patients }}=0.87, \mathrm{SE}=0.27, t(164)=3.26$, $P=.002$, ES $r=.25$ and $B_{\text {partners }}=0.81, \mathrm{SE}=0.16$, $t(164)=5.03, P<.001$, ES $r=.37$, were more satisfied with their relationships (see Table 2). Importantly, these main effects were qualified by a two-way interaction between spousal active engagement and past spousal supportiveness, $B_{\text {patients }}=-0.86, \mathrm{SE}=0.35, t(164)=-2.50$, $P=.014$, ES $r=.19$ and $B_{\text {partners }}=-0.47, \mathrm{SE}=0.20$, $t(164)=-2.35, P=.020$, ES $r=.18$. To better understand these interactions, we calculated the simple slopes for the associations between spousal active engagement and relationship satisfaction at two levels of past spousal supportiveness (i.e., \pm 1 standard deviation from its mean) for patients and partners, separately. As depicted in Fig. 1, spousal active engagement was associated with greater relationship satisfaction in patients if past spousal supportiveness was relatively low, $B=0.88, \quad \mathrm{SE}=0.28$, $t(164)=3.14, P=.002$. This association was not significant if spousal active engagement was relatively high, $B=-0.03, \mathrm{SE}=0.17, t(164)=-0.17, P=0.867$. In other words, especially the combination of low levels of spousal active engagement and low past spousal supportiveness was associated with relatively low levels of relationship satisfaction. The same pattern was found for partners, that is spousal active engagement was associated with greater relationship satisfaction in partners if past spousal supportiveness was relatively low, $B=0.75$, $\mathrm{SE}=0.20, t(164)=3.71, P<.001$. This association was not significant if spousal active engagement was relatively high, $B=0.26, \mathrm{SE}=0.17, t(164)=1.49, P=0.139$. 


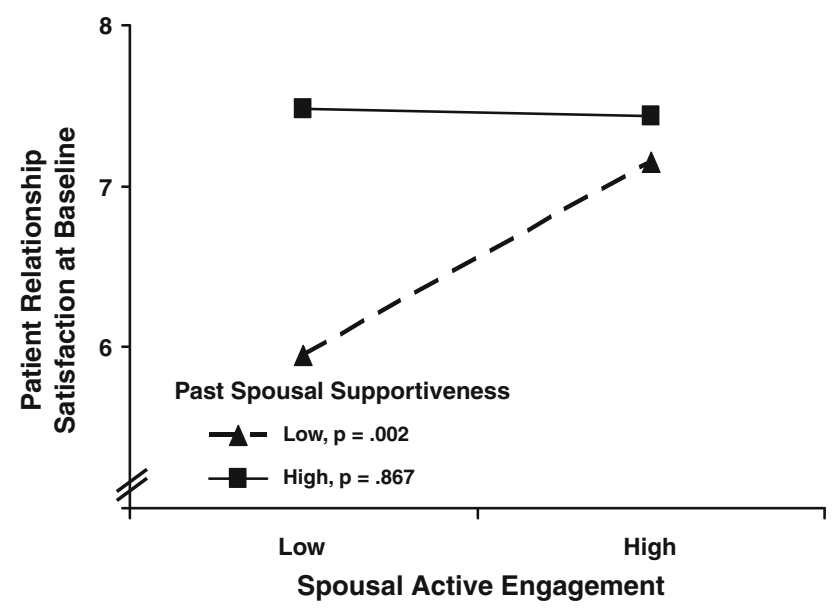

Fig. 1 Association between spousal active engagement and relationship satisfaction at baseline in patients as a function of past spousal supportiveness

\section{Spousal protective buffering and past spousal supportiveness}

In addition to the main effects of past spousal supportiveness reported above, this analysis also revealed main effects for spousal protective buffering, although only approaching significance for patients. Patients, $B=-0.34, \mathrm{SE}=0.18$, $t(162)=-1.92, P=.057$, ES $r=.15$, and partners, $B=-0.34, \mathrm{SE}=0.12, t(162)=-2.93, P=.004, \mathrm{ES}$ $r=.22$, who reported more protective buffering by the spouse reported less relationship satisfaction. The results also showed an interaction effect for patients, $B=1.10$, $\mathrm{SE}=0.41, t(162)=2.67, P=.009, \mathrm{ES} r=.21$, but not for partners, $B=0.25, \mathrm{SE}=0.28, t(162)=0.87, P=.387$, ES $r=.07$. As depicted in Fig. 2, spousal protective buffering was associated with lower relationship satisfaction in patients if past spousal supportiveness was relatively low,

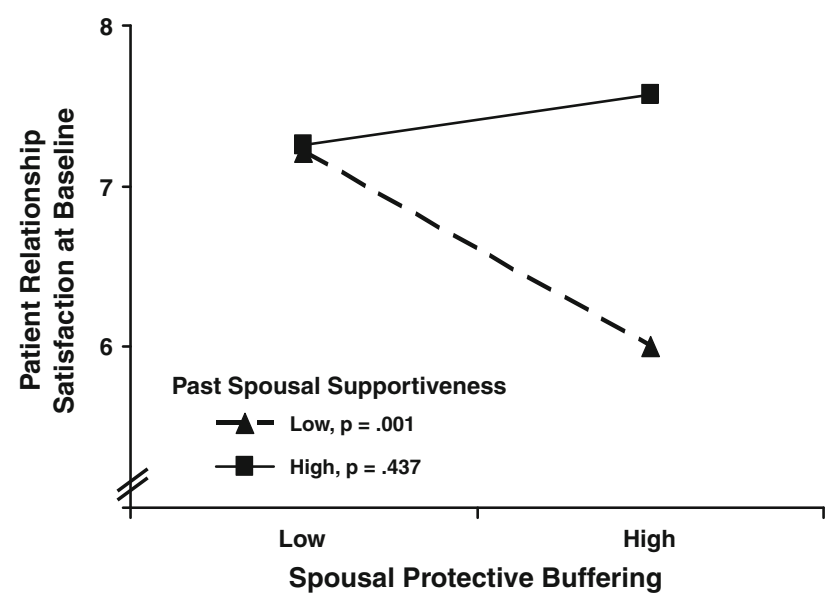

Fig. 2 Association between spousal protective buffering and relationship satisfaction at baseline in patients as a function of past spousal supportiveness
$B=-0.92, \mathrm{SE}=0.26, t(162)=-3.54, P=.001$. This association was not significant if past spousal supportiveness was relatively high, $B=0.23, \mathrm{SE}=0.30, t(162)=0.780$, $P=.437$. In other words, the combination of high levels of spousal protective buffering and low past spousal supportiveness was especially associated with relatively low levels of relationship satisfaction.

Longitudinal analyses

\section{Spousal active engagement and past spousal supportiveness}

The first prospective analysis revealed no effects other than a main effect of relationship satisfaction at baseline, for both patients, $B=0.84, \quad \mathrm{SE}=0.14, \quad t(131)=6.07$, $P<.001$, ES $r=.47$, and partners, $B=0.64, \mathrm{SE}=0.23$, $t(131)=2.83, P=.006$, ES $r=.24$ (see Table 3 ).

\section{Spousal protective buffering and past spousal supportiveness}

In addition to the main effect of relationship satisfaction at baseline, the second prospective analysis yielded a significant main effect of spousal protective buffering for patients, $B=-0.29, \mathrm{SE}=0.13, t(130)=-2.16, P=.033, \mathrm{ES}$ $r=.19$. This finding indicates that more spousal protective buffering at baseline was associated with less future satisfaction in patients. For partners, we found an interaction between protective buffering and past spousal supportiveness, $B=-0.67$, SE $=0.25, t(130)=-2.73, P=.008$, ES $r=.23$. As depicted in Fig. 3, spousal protective buffering at baseline was associated with lower future relationship satisfaction in partners if past spousal supportiveness was relatively high, $B=-0.37, \mathrm{SE}=0.12$, $t(130)=-3.13, P=.003$. This association was not significant if partner past spousal supportiveness was relatively low, $B=0.34$, $\mathrm{SE}=0.21, t(130)=1.64, P=.102$. These findings suggest that instead of mitigating the negative association between spousal protective buffering and relationship satisfaction, past spousal supportiveness strengthens this negative association over time.

\section{Discussion}

The goal of the current study was to examine the role of past spousal supportiveness as a moderator of the link between current spousal supportive behavior and relationship satisfaction in couples coping with cancer. Overall, the cross-sectional findings are in line with the proposed mitigating effect of past spousal support. Specifically, spousal active engagement was associated with greater relationship 
Table 3 Hierarchical linear model (HLM): prospective associations between spousal support and future relationship satisfaction as a function of past spousal supportiveness

\begin{tabular}{|c|c|c|c|c|c|c|c|c|c|c|}
\hline & \multicolumn{5}{|c|}{ Patient relationship satisfaction at follow-up } & \multicolumn{5}{|c|}{ Partner relationship satisfaction at follow-up } \\
\hline & $B$ & SE & $t$ & $P$ & $\mathrm{ES}(r)$ & $B$ & SE & $t$ & $P$ & $\mathrm{ES}(r)$ \\
\hline \multicolumn{11}{|l|}{ Active engagement analysis ${ }^{\mathrm{a}}$} \\
\hline Intercept & 6.71 & 0.09 & 76.08 & $<.001$ & - & 6.73 & 0.11 & 59.00 & $<.001$ & - \\
\hline Baseline relationship satisfaction & 0.84 & 0.14 & 6.07 & $<.001$ & .47 & 0.64 & 0.23 & 2.83 & .006 & .24 \\
\hline Past spousal supportiveness (PSS) & 0.12 & 0.25 & 0.49 & 623 & .04 & 0.31 & 0.25 & 1.24 & .219 & .11 \\
\hline Spousal active engagement (SAE) & 0.12 & 0.13 & 0.88 & .378 & .08 & 0.18 & 0.20 & 0.91 & .363 & .08 \\
\hline $\mathrm{PSS} \times \mathrm{SAE}$ & -0.10 & 0.31 & -0.33 & .739 & .03 & 0.15 & 0.28 & 0.54 & .591 & .05 \\
\hline \multicolumn{11}{|l|}{ Protective buffering analysis ${ }^{\mathrm{b}}$} \\
\hline Intercept & 6.73 & 0.07 & 89.83 & $<.001$ & - & 6.73 & 0.09 & 76.42 & $<.001$ & - \\
\hline Baseline relationship satisfaction & 0.81 & 0.12 & 6.71 & $<.001$ & .51 & 0.70 & 0.19 & 3.73 & $<.001$ & .31 \\
\hline Past spousal supportiveness (PSS) & 0.19 & 0.18 & 1.03 & .304 & .09 & 0.24 & 0.24 & 1.03 & .308 & .09 \\
\hline Spousal protective buffering (SPB) & -0.29 & 0.13 & -2.16 & .033 & .19 & -0.01 & 0.11 & -0.13 & .897 & .01 \\
\hline PSS $\times$ SPB & 0.01 & 0.17 & 0.05 & .961 & $<.01$ & -0.67 & 0.25 & -2.73 & .008 & .23 \\
\hline
\end{tabular}

Effect size $r$ for each $t$ was computed with the following equation: $r=\operatorname{sqrt}\left[t^{2} /\left(t^{2}+d f\right)\right]$

${ }^{\text {a }} d f=131$

${ }^{\mathrm{b}} d f=130$

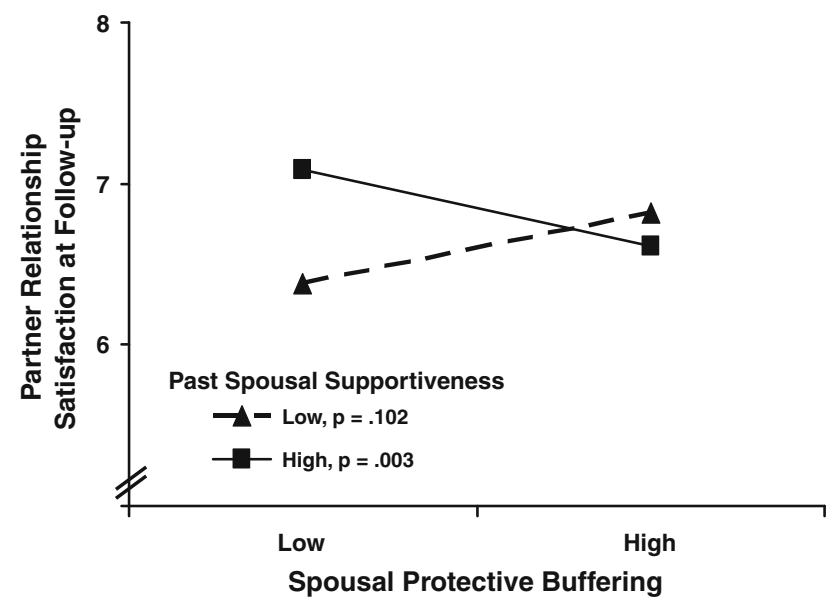

Fig. 3 Association between spousal protective buffering and relationship satisfaction at follow-up in partners as a function of past spousal supportiveness, controlling for baseline relationship satisfaction

satisfaction in patients and partners only if past spousal supportiveness was relatively low. In a similar vein, we found that spousal protective buffering was associated with lower relationship satisfaction in patients only if past spousal supportiveness was relatively low. Put differently, in the context of low spousal supportiveness, individuals reported low levels of relationship satisfaction if current spousal active engagement was low and/or current spousal protective buffering was high. If past spousal support was high, both patients and partners rated the quality of their relationship relatively high, regardless of their spouses' current supportive behavior.
As we pointed out in the introduction, previous research has shown that individuals who perceived overall support to be high interpreted the same current behaviors of a significant other as more supportive than did individuals who perceived overall support to be low (Lakey and Cassady 1990; Lakey and Dickinson 1994; Pierce et al. 1992; Ross et al. 1999). Such an attributional process in which general perceptions of the spouse or the relationship influence the interpretation of current behaviour could explain our results. Individuals who felt highly supported by their spouse in the past-i.e., before the cancer diagnosismay have made benign attributions for their partners' current behavior. Specifically, they may have ascribed the high levels of active engagement and low levels of protective buffering to stable characteristics of the spouse, while low levels of active engagement and high levels of protective buffering were ascribed to external causes. Such a benign attribution would enable individuals to maintain their relationship satisfaction by allowing or sustaining the belief that the necessary spousal support will be forthcoming in the future.

With respect to spousal protective buffering, we found the hypothesized effect for patients, but not for partners. Perhaps the psychosocial oncological context provides an explanation. At baseline, the couples were still in the acute phase, during which the patient was recovering from treatment or still undergoing treatment. At this time, the caregiving role may have been especially salient for partners. More specifically, partners may have felt a strong need to take care of the patient. In order to fulfill their caregiving role, however, partners may depend on their ill 
spouses for information about patients' worries, feelings, and needs. Therefore, partners who perceived relatively high levels of spousal protective buffering may have felt thwarted in their efforts to fulfill the caregiving role, even if they perceived past spousal supportiveness to be relatively high. As a consequence, partners who perceived relatively high levels of spousal protective buffering may have felt less satisfied with their relationship than partners who perceived relatively low levels of spousal protective buffering.

We should use caution when interpreting the longitudinal findings as these were less consistent. Specifically, spousal active engagement was not found to be associated with changes in marital satisfaction, while spousal protective buffering was, albeit the pattern of results differed somewhat for patients and partners. Future relationship satisfaction in patients was lower if their partners used relatively high levels of protective buffering, regardless of whether their partners had been supportive in the past. The follow-up assessment reflects the period in which patients generally try to resume normal life. Perhaps, this is more difficult for patients who perceived relatively high levels of spousal protective buffering during treatment. These patients may hold their partners partly responsible for having difficulty to come to terms with their disease which is reflected in lower relationship satisfaction scores. Our findings suggest that the shutting down of lines of communication represented by high levels of protective buffering leave long lasting effects on patients perceptions of their relationships. On the other hand, our findings for active engagement indicate that the effects are limited to the acute phase, suggesting that the negative effects of a partner's failure to engage in active engagement may be time-limited and easier for patients to recover from once the acute period of need is over. For partners, it appears that over time the negative association between protective buffering and marital satisfaction was even stronger if patients had been supportive in the past. Those partners who perceived their spouses as supportive prior to diagnosis and as low in protective buffering post-diagnosis evidenced the highest levels of relationship satisfaction. Overall, the longitudinal findings seem to suggest that there are limits to individuals' tendency to use benign attributions and to show forgiveness for their partners' unresponsiveness.

Relatively few previous studies have examined associations of active engagement and protective buffering in relation to relationship satisfaction over time, and these have reported nonsignificant associations in a sample of patients with breast cancer (Hinnen et al. 2008a), a sample of couples in which one partner received a hematopoietic stem cell transplantation (Langer et al. 2009), and a sample of healthy couples (Bodenmann et al. 2006). Obviously, further longitudinal work is needed to fully understand possible consequences of spousal behavior, such as active engagement and protective buffering-possibly in combination with spousal supportiveness before the onset of illness-on marital functioning over time.

This study has several noteworthy strengths, such as a longitudinal design and data obtained from both members of couples coping with colorectal cancer, which were analyzed taking into account their interdependency. However, this study has also some limitations. First, although our cross-sectional findings are in line with our hypotheses based on attributional processes in marriage, we did not measure the participants' attributions regarding current spousal supportive behavior. Second, the retrospective assessment of past spousal support may have influenced the findings. It may be that participants' perceptions of past spousal support are colored by their perceptions of current spousal behavior. In other words, the retrospective assessment of past spousal support may have increased the associations with current spousal behavior. Third, the response rate was not very high, which may have introduced some bias. Perhaps only couples who showed high marital functioning participated in our study. However, there are no indications that this was the case. Specifically, the scores of our sample on relationship satisfaction were comparable to the scores of a reference group of Dutch adults (Schroevers et al. 2004). Furthermore, it points out a broader problem recognized in this literature, namely that it is difficult to recruit couples; it is not uncommon for studies of couples dealing with cancer, especially longitudinal and observational studies, to report relatively low response rates (Badr and Taylor 2009; Hinnen et al. 2008b; Langer et al. 2009; Manne et al. 2004). Nevertheless, replication in larger studies with higher response rates that include measurements of the attributional process would be an important next step to further increase our knowledge of dyadic coping with cancer.

To conclude, our cross-sectional results indicate that relationship satisfaction can be maintained if past spousal supportiveness is high, even if the partner is currently not very responsive to the individual's needs. However in the long run, hiding concerns and minimizing the other partner's concerns appears to be harmful in that it is negatively associated with future relationships satisfaction. Therefore, it may be helpful to encourage couples to be actively engaged and to reduce protective buffering. Indeed, previous intervention studies for couples dealing with cancer that focused on dyadic coping have shown that both relationship satisfaction and emotional well-being may improve in patients and their partners (Baucom et al. 2009; Kuijer et al. 2004). Overall, our research supports the idea that dyadic coping processes should be understood in the interpersonal context in which these occur. 
Acknowledgments This research was supported by a grant from the Dutch Cancer Society (KWF); Contract grant number: RUG 02-2581.

Open Access This article is distributed under the terms of the Creative Commons Attribution Noncommercial License which permits any noncommercial use, distribution, and reproduction in any medium, provided the original author(s) and source are credited.

\section{References}

Arrindell, W. A., Boelens, W., \& Lambert, H. (1983). On the psychometric properties of the Maudsley Marital Questionnaire (MMQ): Evaluation of self-ratings in distressed and 'normal' volunteer couples based on the Dutch version. Personality and Individual Differences, 4, 293-306.

Badr, H., \& Taylor, C. L. C. (2009). Sexual dysfunction and spousal communication in couples coping with prostate cancer. PsychoOncology, 18, 735-746.

Baucom, D. H., Porter, L. S., Kirby, J. S., Gremore, T. M., Wiesenthal, N., Aldridge, W., et al. (2009). A couple-based intervention for female breast cancer. Psycho-Oncology, 18, 276-283.

Berg, C. A., \& Upchurch, R. (2007). A developmental-contextual model of couples coping with chronic illness across the adult life span. Psychological Bulletin, 133, 920-954.

Bodenmann, G., Pihet, S., \& Kayser, K. (2006). The relationship between dyadic coping and marital quality: A 2-year longitudinal study. Journal of Family Psychology, 20, 485-493.

Bradbury, T. N., \& Fincham, F. D. (1990). Attributions in marriagereview and critique. Psychological Bulletin, 107, 3-33.

Bradbury, T. N., \& Karney, B. R. (1993). Longitudinal-study of marital interaction and dysfunction-review and analysis. Clinical Psychology Review, 13, 15-27.

Bradbury, T. N., Campbell, S. M., \& Fincham, F. D. (1995). Longitudinal and behavioral-analysis of masculinity and femininity in marriage. Journal of Personality and Social Psychology, 68, 328-341.

Bradbury, T. N., Fincham, F. D., \& Beach, S. R. H. (2000). Research on the nature and determinants of marital satisfaction: A decade in review. Journal of Marriage and the Family, 62, 964-980.

Buunk, B. P., Berkhuysen, M. A., Sanderman, R., Nieuwland, W., \& Ranchor, A. V. (1996). Actieve betrokkenheid, beschermend bufferen en overbescherming: Meetinstrumenten voor de rol van de partner bij hartrevalidatie. [The role of the partner in heart disease: Active engagement, protective buffering, and overprotection]. Gedrag \& Gezondheid, 24, 304-313.

Christensen, A., \& Heavey, C. L. (1990). Gender and social-structure in the demand withdraw pattern of marital conflict. Journal of Personality and Social Psychology, 59, 73-81.

Coyne, J. C., \& DeLongis, A. (1986). Going beyond social supportthe role of social relationships in adaptation. Journal of Consulting and Clinical Psychology, 54, 454-460.

Crowe, M. J. (1978). Conjoint marital-therapy-controlled outcome study. Psychological Medicine, 8, 623-636.

De Ridder, D. T. D., Schreurs, K. M. G., \& Kuijer, R. G. (2005). Is spousal support always helpful to patients with asthma or diabetes? A prospective study. Psychology \& Health, 20, 497-508

Fincham, F. D., \& Bradbury, T. N. (1987). The impact of attributions in marriage- a longitudinal analysis. Journal of Personality and Social Psychology, 53, 510-517.

Fincham, F. D., \& Bradbury, T. N. (1993). Marital satisfaction, depression, and attributions-a longitudinal analysis. Journal of Personality and Social Psychology, 64, 442-452.
Fincham, F. D., Bradbury, T. N., Arias, I., Byrne, C. A., \& Karney, B. R. (1997). Marital violence, marital distress, and attributions. Journal of Family Psychology, 11, 367-372.

Graham, J. M., \& Conoley, C. W. (2006). The role of marital attributions in the relationship between life stressors and marital quality. Personal Relationships, 13, 231-241.

Hagedoorn, M., Kuijer, R. G., Buunk, B. P., Dejong, G. M., Wobbes, T., \& Sanderman, R. (2000). Marital satisfaction in patients with cancer: Does support from intimate partners benefit those who need it the most? Health Psychology, 19, 274-282.

Hagedoorn, M., Sanderman, R., Bolks, H. N., Tuinstra, J., \& Coyne, J. C. (2008). Distress in couples coping with cancer: A metaanalysis and critical review of role and gender effects. Psychological Bulletin, 134, 1-30.

Heider, F. (1958). The psychology of interpersonal relations. New York: Wiley.

Henry, N. J. M., Berg, C. A., Smith, T. W., \& Florsheim, P. (2007). Positive and negative characteristics of marital interaction and their association with marital satisfaction in middle-aged and older couples. Psychology and Aging, 22, 428-441.

Hinnen, C., Hagedoorn, M., Sanderman, R., \& Ranchor, A. V. (2007). The role of distress, neuroticism and time since diagnosis in explaining support behaviors in partners of women with breast cancer: Results of a longitudinal analysis. Psycho-Oncology, 16, 913-919.

Hinnen, C., Hagedoorn, M., Ranchor, A. V., \& Sanderman, R. (2008a). Relationship satisfaction in women: A longitudinal case-control study about the role of breast cancer, personal assertiveness, and partners' relationship-focused coping. British Journal of Health Psychology, 13, 737-754.

Hinnen, C., Ranchor, A. V., Sanderman, R., Snijders, T. A. B., Hagedoorn, M., \& Coyne, J. C. (2008b). Course of distress in breast cancer patients, their partners, and matched control couples. Annals of Behavioral Medicine, 36, 141-148.

Holtzworth-Munroe, A., \& Jacobson, N. S. (1985). Causal attributions of married-couples-when do they search for causes-what do they conclude when they do. Journal of Personality and Social Psychology, 48, 1398-1412.

Karney, B. R., \& Bradbury, T. N. (2000). Attributions in marriage: State or trait? A growth curve analysis. Journal of Personality and Social Psychology, 78, 295-309.

Kenny, D. A., Kashy, D. A., \& Cook, W. L. (2006). Dyadic data analysis. New York: Guilford Press.

Kreft, I. G. G., Deleeuw, J., \& Aiken, L. S. (1995). The effect of different forms of centering in hierarchical linear-models. Multivariate Behavioral Research, 30, 1-21.

Kuijer, R. G., Ybema, J. F., Buunk, B. P., De Jong, G. M., Thijs-Boer, F., \& Sanderman, R. (2000). Active engagement, protective buffering, and overprotection: Three ways of giving support by intimate partners of patients with cancer. Journal of Social and Clinical Psychology, 19, 256-275.

Kuijer, R. G., Buunk, B. P., De Jong, G. M., Ybema, J. F., \& Sanderman, R. (2004). Effects of a brief intervention program for patients with cancer and their partners on feelings of inequity, relationship quality and psychological distress. Psycho-Oncology, 13, 321-334.

Lakey, B., \& Cassady, P. B. (1990). Cognitive-processes in perceived social support. Journal of Personality and Social Psychology, 59, 337-343.

Lakey, B., \& Dickinson, L. G. (1994). Antecedents of perceived support-is perceived family environment generalized to new social relationships. Cognitive Therapy and Research, 18, $39-53$.

Langer, S. L., Brown, J. D., \& Syrjala, K. L. (2009). Intrapersonal and interpersonal consequences of protective buffering among cancer patients and caregivers. Cancer, 115, 4311-4325. 
Laurenceau, J. P., \& Bolger, N. (2005). Using diary methods to study marital and family processes. Journal of Family Psychology, 19, 86-97.

Manne, S., \& Badr, H. (2008). Intimacy and relationship processes in couples' psychosocial adaptation to cancer. Cancer, 112, 2541-2555.

Manne, S., Ostroff, J., Sherman, M., Heyman, R. E., Ross, S., \& Fox, K. (2004). Couples' support-related communication, psychological distress, and relationship satisfaction among women with early stage breast cancer. Journal of Consulting and Clinical Psychology, 72, 660-670.

McNulty, J. K., \& Karney, B. R. (2001). Attributions in marriage: Integrating specific and global evaluations of a relationship. Personality and Social Psychology Bulletin, 27, 943-955.

Pierce, G. R., Sarason, B. R., \& Sarason, I. G. (1992). General and specific support expectations and stress as predictors of perceived supportiveness-an experimental study. Journal of Personality and Social Psychology, 63, 297-307.

Raudenbush, S. W., \& Bryk, A. S. (2002). Hierarchical linear models: Applications and data analysis methods (2nd ed.). Newbury Park, CA: Sage.
Ross, L. T., Lutz, C. J., \& Lakey, B. (1999). Perceived social support and attributions for failed support. Personality and Social Psychology Bulletin, 25, 896-908.

Schroevers, M. J., Ranchor, A. V., \& Sanderman, R. (2004). The role of age at the onset of cancer in relation to survivors' long-term adjustment: A controlled comparison over an eight-year period. Psycho-Oncology, 13, 740-752.

Waldinger, R. J., \& Schulz, M. S. (2006). Linking hearts and minds in couple interactions: Intentions, attributions, and overriding sentiments. Journal of Family Psychology, 20, 494-504.

Williamson, G. M., \& Schulz, R. (1995). Caring for a family member with cancer-past communal behavior and affective reactions. Journal of Applied Social Psychology, 25, 93-116.

Williamson, G. M., Shaffer, D. R., \& Schulz, R. (1998). Activity restriction and prior relationship history as contributors to mental health outcomes among middle-aged and older spousal caregivers. Health Psychology, 17, 152-162.

Wunderer, E., \& Schneewind, K. A. (2008). The relationship between marital standards, dyadic coping and marital satisfaction. European Journal of Social Psychology, 38, 462-476. 